\title{
The Non-Split Domination Number of a Jump Graphs
}

\author{
N. Pratap Babu Rao \\ Associate Professor S.G., \\ Degree College KOPPAL, Karnataka, India
}

\author{
Sweta N. \\ Lecturer Veerasaiva College Ballari \\ Karnataka, India
}

\begin{abstract}
A dominating set D of a jump graph $J(G)$ is a non split dominating set of a jump graph if the induced sub graph < $E(J(G))-D>$ is connected the non split domination $V_{n s} J(G)$ is minimum cardinality of a non-split dominating set. In this paper many bound of $V_{n s} J(G)$ are obtained and its exact values of some standard graphs are found. Also its relationship with other parameters are investigated.
\end{abstract}

\section{Keywords}

Graphs, domination number, Non split domination number

\section{INTRODUCTION}

The graph considered here are finite, undirected, non trivial and connected without loops and multiple edges.

A set $D \subseteq V(J(G))$ is a dominating set of jump graph. If every vertex not in $\mathrm{D}$ is adjacent to a vertex $\mathrm{D}$. The domination number of the jump graph $\mathrm{J}(\mathrm{G})$.

The dominating set $\mathrm{D} \subseteq \mathrm{V}(\mathrm{J}(\mathrm{G})$ ) is called a connected dominating set of a jump graph is the induced sub graph $\langle\mathrm{D}\rangle$ is connected. The minimum cardinality of the connected dominating set in $\mathrm{J}(\mathrm{G})$ is its dominating number denoted by

$$
V_{c}(J(G)) \text {. }
$$

A dominating set $\mathrm{D}$ of a jump graph $\mathrm{J}(\mathrm{G})=(\mathrm{v}(\mathrm{J}(\mathrm{G}), \mathrm{E}(\mathrm{JG}))$ is a split dominating set if the induced sub graph $V(J(G))-D$ disconnected. The split dominating number $\sqrt{s}_{\mathrm{s}}(\mathrm{J}(\mathrm{G}))$ of $\mathrm{J}(\mathrm{G})$ is the minimum cardinality of a split dominating set.

The reader is referred to [1] [2] [3] and [4]for survey or results on domination.

Any undefined terms in this paper may be found in Harary[5] unless staed, the graph has $p$ vertices and $q$ edges.

The purpose of this paper is to introduce the concept of Non split domination.

A dominating set $\mathrm{D}$ of a graph $\mathrm{J}(\mathrm{G})$ is a nonsplit dominating set. If the induced sub graph $\mathrm{v}(\mathrm{J}(\mathrm{G}))-\mathrm{D}$ is connected. The non split domination number $V_{n s}(J(G))$ of $J(G)$ is the minimum cardinality of a non split dominating set.

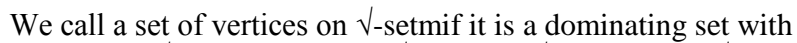
cardinality $\sqrt{ }(\mathrm{J}(\mathrm{G}))$ similar a $\sqrt{c}_{\mathrm{c}}-$ set, a $\sqrt{s}_{\mathrm{s}^{-}}$set and a $\sqrt{n s}_{\mathrm{ns}^{-}}$set are defined.

\section{RESULTS}

We start with some elementary results. Since their proofs are trivial we omit the same.

Theorem 2.1: For any graph $\mathrm{G}$

$$
\sqrt{ }(\mathrm{J}(\mathrm{G})) \leq \sqrt{\text { ns }}_{\mathrm{S}}(\mathrm{J}(\mathrm{G}))
$$

Theorem 2.2. For any graph $\mathrm{G}$

$\sqrt{ }(\mathrm{J}(\mathrm{G}))=\min \left\{\sqrt{ }_{\mathrm{s}}(\mathrm{J}(\mathrm{G})), \sqrt{ }_{\mathrm{ns}}(\mathrm{J}(\mathrm{G}))\right\}$
In [3] Cockayne and Hedetniemi gave necessary and sufficient conditions for a minimal dominating set.

Theorem A: A dominating set $\mathrm{D}$ of a graph $\mathrm{G}$ is minimal if and only if for each vertex $\mathrm{v} \in \mathrm{D}$ one of the following condition is satisfy

(i) if there exists a vertex $u \in V-D$ such that $N[u] \cap D=\{v\}$ and

(ii) $\mathrm{v}$ is an isolated vertex in $\langle\mathrm{D}\rangle$

Theorem 2.3: A non split dominating set $D$ of $J(G)$ is minimal if and only if for each vertex $\mathrm{v}$ in $\mathrm{D}$ one of the following conditions is satisfied.

(i) If there exists a vertex $\mathrm{u} \in \mathrm{V}(\mathrm{J}(\mathrm{G}))-\mathrm{D}$ such that $\mathrm{N}[\mathrm{u}] \cap \mathrm{D}=\{\mathrm{v}\}$.

(ii) $\mathrm{v}$ is an isolated vertex in $\langle\mathrm{D}\rangle$ and

(iii) $\mathrm{N}(\mathrm{v}) \cap(\mathrm{V}(\mathrm{J}(\mathrm{G}))-\mathrm{D})=\varnothing$

Proof: Suppose D is minimal. On the contrary, if there exists a vertex $v \in D$ such that $v$ does not satisfy any of the given conditions then by Theorem $A D^{\prime}=D-\{v\}$ is a dominating set of $\mathrm{J}(\mathrm{G})$ and by (iii) ( $\mathrm{v}(\mathrm{J}(\mathrm{G}))-\mathrm{D}^{\prime}$ is connected. This implies that $D^{\prime}$ is a non split dominating set of $J(G)$, a contradiction This proves the necessity sufficiency is straight forward.

Next we observe a relationship between $V_{n s}(J(G))$ and $V_{\text {ns }}(J(H))$ where $J(H)$ is any spanning sub graph of $J(G)$ we omit the proof

Theorem 2.4. For any spanning sub graph $J(H)$ of $J(G)$

$V_{\text {ns }}(\mathrm{J}(\mathrm{G})) \leq V_{\text {ns }}(\mathrm{J}(\mathrm{H}))$.

We obtain lower and upper bounds on $V_{n s}(J(G))$ respectively.

Theorem 2.5 For any graph $\mathrm{J}(\mathrm{G})$

$V_{\text {ns }}(J(G)) \geq \frac{(2 p-q-1)}{2}$

Proof: Let D be a $\sqrt{n s}_{\mathrm{ns}}(\mathrm{J}(\mathrm{G}))$-set of $\mathrm{J}(\mathrm{G})$ Since

$(\mathrm{v}(\mathrm{J}(\mathrm{G})-\mathrm{D})$ is connected.

$\mathrm{q} \geq|\nabla(\mathrm{J}(\mathrm{G}))-\mathrm{D}|+|\mathrm{V}(\mathrm{J}(\mathrm{G}))-\mathrm{D}|-1$

This proves the result..

Theorem 2.6. For any graph $\mathrm{G}$

$V_{\text {ns }}(J(G)) \leq p-W(J(G))$ is the Clique number of $G$.

Proof: Let $S$ be a set of vertices of $J(G)$ such that $\langle S\rangle$ is complete with $|S|=w(j(g))$ Then for any

$\mathrm{u} \in \mathrm{S}(\mathrm{V}(\mathrm{J}(\mathrm{G}))-\mathrm{S}) \cup\{\mathrm{u}\}$ is a non split dominating set of $\mathrm{G}$.

Then the result holds. 
Now we list the exact values of $V_{\text {ns }}(J(G))$ for some standard graphs..

\section{Proposition 2.7.}

(i) For any complete graph $\mathrm{K}_{\mathrm{p}}$ with $\mathrm{p} \geq 2$ vertices $V_{\text {ns }}\left(J\left(K_{\mathrm{p}}\right)\right)=1$.

(ii) For any complete bipartite graph $\mathrm{K}_{\mathrm{m}, \mathrm{n}}$ with 2 $\leq \mathrm{m} \leq \mathrm{n} V_{\mathrm{ns}}\left(\mathrm{J}\left(\mathrm{K}_{\mathrm{m}, \mathrm{n}}\right)=2\right.$

(iii) For any cycle $c_{p} V_{n s}\left(J\left(C_{p}\right)\right)=p-2$

(iv) For any wheel $\mathrm{W}_{\mathrm{p}} \sqrt{\mathrm{ns}}_{\mathrm{s}}\left(\mathrm{J}\left(\mathrm{W}_{\mathrm{p}}\right)\right)=1$

(v) For any path $\mathrm{P}_{\mathrm{p}}$ with $\mathrm{p} \geq 3$ vertices $\sqrt{n s}_{\mathrm{ns}}\left(\mathrm{J}\left(\mathrm{P}_{\mathrm{p}}\right)\right)=$ $\mathrm{p}-2$

(vi) Our next result sharpens the inequality of Theorem 2.6 for tree.

Theorem 2.8. If $\mathbf{T}$ is a Tree which is not a star, then $V_{\text {ns }}(\mathrm{J}(\mathrm{T})) \leq \mathrm{p}-2$.

Proof: Since, $t$ is not a star, there exists two adjacent cut vertices $\mathrm{u}$ and $\mathrm{v}$ with $\operatorname{deg} \mathrm{u}, \operatorname{deg} \mathrm{v} \geq 2$ This implies that $\mathrm{v}$ $(J(G))-\{u, v\}$ is a non split dominating set of $J(T)$.

Thus the result holds.

Theorem 2.9. if $k(J(G)) \geq \beta_{0}(J(G))$ then

$V_{\text {ns }}(J(G))=\sqrt{ }(J(G))$ where $k(J(G))$ is the connectivity of jump graph $J(G)$ and $\beta_{0}(J(G))$ is the independence number of $J(G)$.

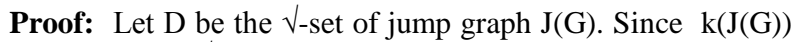
$>\beta_{0}(\mathrm{~J}(\mathrm{G})) \geq \sqrt{ }(\mathrm{J}(\mathrm{G}))$. It implies that $\langle\mathrm{V}(\mathrm{J}(\mathrm{G}))-\mathrm{D}\rangle$ is connected. This proves that $\mathrm{D}$ is a $\sqrt{n s}_{\text {s }}$-set of $\mathrm{J}(\mathrm{G})$.

Hence the result.

Theorem 2.10.: Let $d$ be a $V_{n s}$-set of a connected graph G If no two vertices in $\mathrm{V}(\mathrm{J}(\mathrm{G}))-\mathrm{D}$ are adjacent to a commom vertex in $\mathrm{D}$ then

$V_{\mathrm{ns}}(\mathrm{J}(\mathrm{G}))+\varepsilon(\mathrm{J}(\mathrm{T})) \geq \mathrm{p}$ where $\varepsilon(\mathrm{J}(\mathrm{T}))$ is the maximum number of end vertices in any spanning tree $J(T)$ of $J(G)$..

Proof: Let $D$ be $a V_{n s}$-set of $J(G)$, given in the hypothesis. Since for any two vertices $u, v \in V(J(G))-D$ there exists two vertices $u_{1+} v_{1} \in D$ such that $u_{1}$ is adjacent to $u$ but not $v$ and $\mathrm{v}_{1}$ is adjacent to a vertex $\mathrm{v}$ but not $\mathrm{u}_{1}$. This implies that there exists a spanning tree $\mathrm{J}(\mathrm{T})$ of $\langle\mathrm{V}(\mathrm{J}(\mathrm{G}))-\mathrm{D}\rangle$ in which each vertex of $V(G)-D$ is adjacent to a vertex of $D$.

This proved that $\varepsilon(\mathrm{J}(\mathrm{T})) \geq|\mathrm{V}(\mathrm{J}(\mathrm{G}))-\mathrm{D}|$.

Hence the result holds.
Theorem 2.11.: If $\delta(\mathrm{J}(\mathrm{G}))+\omega(\mathrm{J}(\mathrm{G})) \geq \mathrm{p}+1$ then

$V_{\mathrm{c}}(\mathrm{J}(\mathrm{G}))+V_{\mathrm{ns}}(\mathrm{J}(\mathrm{G})) \leq \mathrm{p}$ where

$\delta(\mathrm{J}(\mathrm{G}))$ is the minimum degree of $\mathrm{J}(\mathrm{G})$.

Proof: By theorem $2.6 V_{\mathrm{ns}}(\mathrm{J}(\mathrm{G})) \leq \mathrm{p}-\omega(\mathrm{J}(\mathrm{G}))+1 \leq \delta(\mathrm{J}(\mathrm{G}))$

Let $d$ be a $V_{n s^{-}}$set of jump graph $J(G)$. Then every ertex in $D$ is adjacent to some vertex in $\mathrm{V}(\mathrm{J}(\mathrm{G}))-\mathrm{D}$ Thus $<. \mathrm{V}(\mathrm{J}(\mathrm{G}))$ $D>$ is a connected dominating set of $J(G)$. Since $<V(J(G))-$ $\mathrm{D}>$ is connected .

Hence $V_{\mathrm{c}}(\mathrm{J}(\mathrm{G}))+\sqrt{\mathrm{ns}}_{\mathrm{J}}(\mathrm{J}(\mathrm{G})) \leq \mathrm{p}$

Theorem 2.12: For any tree

$V_{\text {ns }}(J(T)) \geq p-m$. where $m$ is the number of vertices adjacent to vertices.

Proof: If $\mathrm{J}(\mathrm{T})$ is $\mathrm{K}_{2}$, the result is trivial. If $\mathrm{J}(\mathrm{T})$ has at least three vertices and $D$ is a $V_{n s}$-set of $J(T)$, then each vertex of $\mathrm{V}(\mathrm{J}(\mathrm{G}))-\mathrm{D}$ is a cut vertices of $\mathrm{J}(\mathrm{T})$. Let $\mathrm{S}$ be the set of all cut vertices which are adjacent to end vertices with $|S|=m$ let $u \in$ $\mathrm{V}(\mathrm{J}(\mathrm{G}))-\mathrm{D}$. If $\mathrm{u} \in \mathrm{S}$ then $\mathrm{D}=\mathrm{V}(\mathrm{J}(\mathrm{G}))-\mathrm{S}$ and inequality holds. If $u \notin S$, then there exists a cut vrtex $v \in D$ adjacent to $u$. Further all vertices which are connected to v not through $u$ also belonging to $\mathrm{D}$ This implies that $\mathrm{V}(\mathrm{J}(\mathrm{G}))-\mathrm{D}$ has at most $m$ vertices and inequality holds.

\section{REFERENCES}

[1] G. Chartrand and L.Lesnaik, Graphsand Digraphs chapman and hall Madras (1996)

[2] E.J. Cockayne, Domination of undirected graphs. A survey in theory and applications of GraphsLNM642 springer-verlog 1978 141-147.

[3] E.J. Cockayne and S.T. Hedetniemi a Net work 7(1977)247-261.

[4] 4. F. Harary Graph theory addition Wesley Reading mass (1969).

[5] V.R. Kulli and B. Janakiram The non split domination number of graph Indian. J. phy.appl.Math. 31(40 441447 (2000)

[6] V. R. Kulli and B.Janakiram, The split domination number of a graph Theory Notes of New York New York Academy of Sciences (1997) XXXII 16-19.

[7] E. Sampath Kumar and H.B. Walikar J.Math.Phys.Sci 13 (1979)607-613. 